\title{
Assessing the sustainability of existing buildings using the analytic hierarchy process
}

\author{
Lucio V. Rosa ${ }^{1,}$, Assed N. Haddad ${ }^{2}$ \\ ${ }^{1}$ Federal Fluminense University, Niterói, Brasil \\ ${ }^{2}$ Federal University of Rio de Janeiro, Rio de Janeiro, Brasil
}

\section{Email address:}

villavr@terra.com.br(L.V. Rosa), assed@poli.ufrj.br(A. N. Haddad)

\section{To cite this article:}

Lucio V. Rosa, Assed N. Haddad. Assessing the Sustainability of Existing Buildings Using the Analytic Hierarchy Process. American Journal of Civil Engineering. Vol. 1, No. 1, 2013, pp. 24-30. doi: 10.11648/j.ajce.20130101.14

\begin{abstract}
Relative concepts of sustainability are more and more influenced by societies around the world. The construction industry, especially for building construction development, is being accused of promoting environmental impacts that range from excess use of resources to pollution generation. This paper present an application of the sustainability concept applied to buildings, as well as, a contribution to the development of practices, methodology and tools for evaluation of already existing buildings. In order to achieve that, this study will detail how current systems to evaluate building performance operate, and how can we improve them. The Analytic Hierarchy Process (AHP), a multi-criteria method, is used as a tool to investigate the relative importance of the criteria, sub-criteria and families of indicators established by the researcher and interested parties, and adjust the proposed system to the local culture. AHP usage allowed a deeper insight into the problem.
\end{abstract}

Keywords: Analytic Hierarchy Process, Building Assessment, Green Building

\section{Introduction}

The term sustainable development can take on different meanings among them "quality of life" allowing people to aim to live life in a wholesome environment and design the continuous improvement of the social, economic and environmental conditions for current and future generations[1].

As a result of this awareness process, a significant part of the society is considering the construction sector as one of the main sources of impacts to the environment, taking into account for example, the excessive consumption of resources and the generation of pollution in the phases of construction and use[2] of building materials.

When the occupation period of buildings exhaust $80 \%$ of all the energy expected to be consumed throughout its life cycle, this represent the primary target for the actions aimed at energy efficiency and thereby contribute to reduce the adverse impacts caused by them to the environment, human health and the economy[3].

It should be noted that while the buildings are the largest contributors to environmental degradation they are both important for the sustainability of business and as city dwellers spend $80 \%$ to $90 \%$ of their time indoors may thus contribute significantly to the quality of life[3,4].

At this point it is important to note that a green building can behave in a certain way when subjected to a certain number of requirements. They are expected to minimize the disturbances to the ecosystem and other improvements throughout the life cycle, as well as the optimization of resource management efficiency and operational performance beyond the minimization of risks to human health and to the environment[5].

This focus on reducing environmental impacts raises the need to use a tool for monitoring environmental performance goals that must take into account a set of verifiable criteria and goals for the owners and designers align themselves with high environmental standards[2, 6].

It is worth emphasizing that should be avoided any possibility of mere import of existing methods based on the success achieved in countries with different contexts[7].

Developing nations must address interventions related to sustainable development, primarily for social and economic segments as these issues are at the top of their agendas[8].

Given the potential for significant contribution of universities to find solutions to reverse the trend of environmental degradation in 2005 three hundred deans and university presidents involving forty countries signed a 
document setting out measures in various areas especially in relation to the establishment of programs for the production of knowledge in environmental management[9].

In this respect the design, construction and operation of a school building four aspects of performance are particularly important[10]:

a) Prioritize the use of concepts;

b) Consider seriously the management requirements of the operation and maintenance;

c) Supplement the needs and habits of occupants, and

d) Design new facilities or expansions considering changes and uncertainties.

Due to the importance of the construction industry to the economy of Brazil associated with the issue of increasing search for more efficient buildings we highlight the fact that one of the priorities in research management is the restructuration of this segment of organizations regarding the evaluation of sustainability for new and existing buildings.
It is put as central problem to answer the following question: What are the criteria, sub criteria, families of indicators and relative levels of importance attached to a method of assessing the sustainability of existing buildings, customized for use in the metropolitan region Rio de Janeiro?

\section{Buildings Sustainability Assessment}

There are basically two models for the analysis of environmental performance for buildings. The first and majoritarian model builds on a system that awards points to a select number of parameters, the so-called indicators, according to a scale ranging from a "small impact" to the gradation "huge impact" environmentally[11].

These indicators have weights, explicit or not, that depict the main local environmental problems[7, 8, 11, 12].

Table 1. Comparison between the most important green building rating systems in terms of the weights used in the main categories of evaluation

\begin{tabular}{|c|c|c|c|c|c|}
\hline \multicolumn{6}{|c|}{ Green building rating system } \\
\hline Assessment criteria & LEED & IPT & BREEAM & CASBEE & GBTOOL \\
\hline Energy efficiency & $21,7 \%$ & $20,0 \%$ & $8,3 \%$ & $9,6 \%$ & $4,0 \%$ \\
\hline Water efficiency & $7,3 \%$ & $20,0 \%$ & $4,5 \%$ & $9,1 \%$ & $4,0 \%$ \\
\hline Indoor environment quality & $18,8 \%$ & $6,0 \%$ & $12,4 \%$ & $22,4 \%$ & $23,0 \%$ \\
\hline Waste and material management & $18,8 \%$ & $20,0 \%$ & $9,8 \%$ & $21,1 \%$ & $12,0 \%$ \\
\hline Eco management & $10,1 \%$ & $0,0 \%$ & $14,1 \%$ & $0,0 \%$ & $10,0 \%$ \\
\hline
\end{tabular}

Legend:

Green Building Assessment Tool (GBTooL).

Leadership in Energy and Environmental Design (LEED).

Technological Research Institute of São Paulo (IPT).

Comprehensive Assessment system for Building Environmental Efficiency (CASBEE).

Building Research Establishment Environmental Assessment Method (BREEAM).

Table 1 shows the weights used for the main categories of evaluation of the most important green building rating systems [13].

The second model utilizes the methodology LCA - Life Cycle Assessment, to indicate the best solution in design, materials and options for local utilities, namely: energy supply, waste management, and types of transport[11].

It is worth mentioning that most of the tools focuses almost exclusively on the environmental dimension of sustainability[7, 11, 12].

The most obvious reason for this type of strategy with regard to the sustainability agenda in developed countries absolutely focused on that fruit size of the development model used, which on the one hand led the society to a good quality of life, on the other hand caused marked elimination of natural resources around the globe[7].

Another reason would be the concept of recognizing the right of the "other" that exists in developed countries, be it a neighbor, a worker or a neighborhood, which results in a practical outcome the high level of regulation and democratization in decision making, which is oriented to the production, maintenance and renewal of the urban built environment[7].
In this regard, developing countries must address the interventions towards sustainable development, primarily for the social and economic segments[7, 12].

\section{The Multi Criterion Analysis}

Decision-making is not an act required or clearly identifiable, but a process, i.e., a decision process that includes not only the final act of choice between alternatives, but a complete process of decision with four phases: intelligence, design, choice and review[14].

The decision situations can be classified as choice, classification, ordering, ordered classification, and prioritization. Regarding the decision situations they can be described as follows[15]:

a) Choice: selecting an alternative from a set of feasible alternatives;

b) Classification: classifying viable alternatives in predefined categories;

c) Ordering: establish an ordering of preference for viable alternatives according to a criterion;

d) Ordered classification: determine the classification of alternatives in preset ordered categories; 
e) Priorization: establish a priority order for the elements of a set of alternatives.

The method used in different fields of research is the AHP as it provides the treatment of complex problems with multiple criteria, stakeholders and decision makers, in a scenario of high uncertainty and high risk $[15,16]$.

The AHP provides a good compromise between the target, understanding and objectivity to the extent that is a tool supported by the basic mathematics that enables ordinary people to order tangible and intangible factors in a process of conflict resolution or order of priorities $[15,16$, $17,18,19]$.

Moreover, AHP increases transparency and objectivity in decision-making in that works with multiple agents that can express their preferences, and facilitates the detection of controversial items and provides the establishment of agreements[15, 16, 17, 18, 19].

In practice often results obtained with the use of AHP are corroborated when compared with results obtained by other tools that use more time and resources[16].

At this point, it is important to note that AHP is a method for choosing the best alternative that incorporates qualitative considerations and quantitative factors to the subjective process of decision-making, i.e., allows the decision maker to work with the intuitive, rational and irrational at the same time[18, 19].

The AHP model involves four stages, namely: creation of the decision problem, measurement and data collection, establishment of standard weights, and presentation of summaries of findings solutions to the problem $[15,18,19]$.

In other words are developed four steps: creation of the hierarchy in order to identify the main objective, criteria, sub criteria and alternatives for data collection value judgments issued by experts, the calculation of the priority of each alternative, and analysis consistency[18, 19].

The hierarchical structure used in the formulation of the AHP model allows each member of the group of experts view the issue in a systematic way in terms of relevant criteria and sub criteria. Experts may revise the proposed hierarchical structure if necessary[18, 19, 20, 21].

For the construction of the hierarchy, starting point of the modeling should be met the following steps, as shown in Fig.1 $[18,19]$ :

a) Identification of the central purpose or focus;

b) Determining the set of criteria, properties or viewpoints for the evaluation of sub-criteria, if any, or the alternatives;

c) Determining the set of sub-criteria, if any, for the evaluation of alternatives;

d) Determining the set of feasible alternatives.

It should be noted that the construction of a hierarchy requires knowledge and experience in the study area, and should be performed carefully to represent reliably the problem being treated[18, 19].

After the hierarchical structuring of the problem starts the phase of collecting the value judgments, This phase seeks to answer three main questions: What will be judged?
How to judge? Who should judge?[15, 18, 19].

With regard to the first question the appraiser must conduct a pairwise comparison of the elements of a same layer of the hierarchy in the light of each of the elements in connection positioned on the layer immediately above[15].

Fig. 1 shows the hierarchical structure and Fig. 2 shows the pairwise comparison of the elements of a same layer of the hierarchy[18, 19].

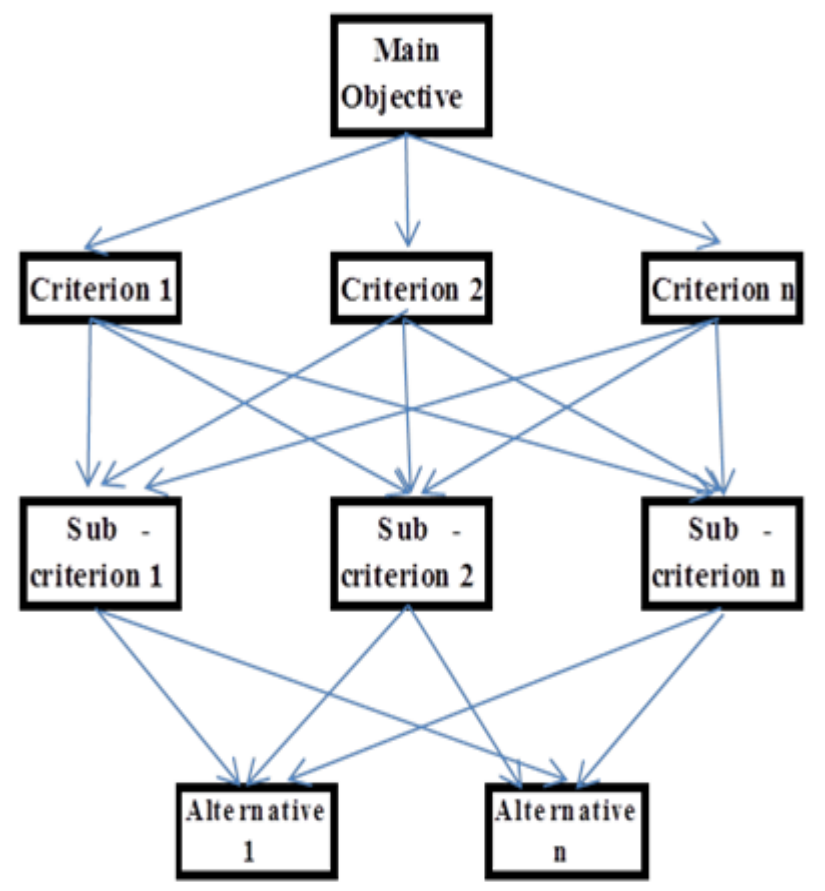

Figure 1. Structuring of the hierarchy

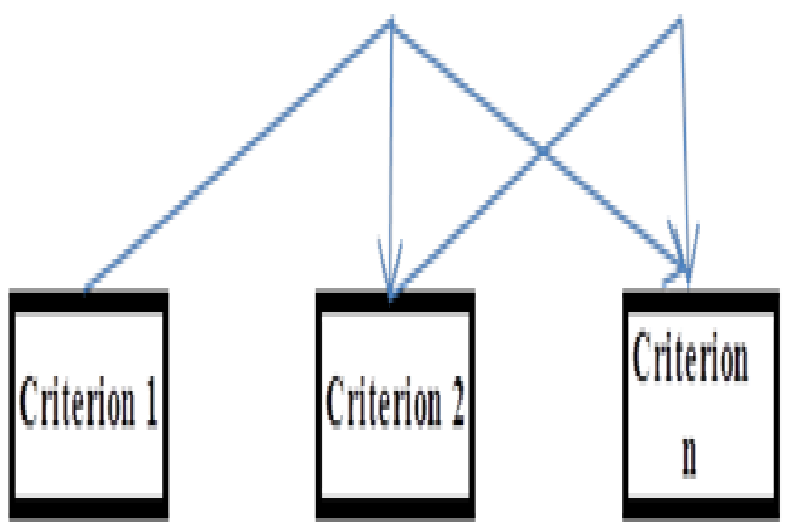

Figure 2. The pairwise comparison of the elements of a same layer of the hierarchy

For the purpose of the trial must be considered the fundamental scale, as shown in Table 2, which employs nine intensity levels of importance that correspond to the numbers 1 through $9[18,19]$. 
Table 2. The fundamental scale of judgment

\begin{tabular}{cc}
\hline Verbal scale & Numerical scale \\
\hline same & 1 \\
slight & 3 \\
little & 5 \\
a lot & 7 \\
extremely & 9 \\
& $2,4,6$ e 8-intermediate levels \\
\hline
\end{tabular}

With regarding, selection of evaluators is essential that they have a broad knowledge about the study area, as well as some experience in the issue of value judgments[15, 18 , $19,22]$.

A good choice of experts contributes significantly to the achievement of good results, since the AHP enables the capture and synthesis of information present in the minds of those experts regardless if qualitative, quantitative, tangible, intangible, subjective or objective[15, 22].

Once the structure was built calculations are then performed in order to establish the prioritization of alternatives. The matrices are then calculated from the lowest level in the hierarchical structure of the AHP framework[15, 16, 18, 19].

Although the employment of specialists for the realization of value judgments, the AHP provides the possibility that these judgments may be inconsistent. In this sense, the AHP allows to assess the consistency and determining the degree of inconsistency in a matrix of parity judgment $[18,19]$.

Finally, the global valuation of each alternative is performed according to the method of weighted sum.

\section{Research Steps}

During the review of the literature related to sustainability assessment of buildings, the first phase of this research, it became apparent that there are few works related to the processing of assessments of sustainability in existing school buildings. Such observation served as the basis for indicating the use of this type of building for the application of the model.

Also in this first phase were analyzed the main sustainability evaluation systems in order to establish a set of variables necessary for structuring tool evaluation from the following assumptions

a) Self-administration by managers directly involved;

b) Success factors when implementing in various contexts.

In the next phase were carried out field visits in order to identify key social, economic and environmental context of the local city of Rio de Janeiro, based on the researcher's observations and the results of informal interviews with key stakeholders in question, namely: sustainability experts' buildings; maintainers, teachers and students, etc...
The third stage consisted of reviewing the bibliography of multi-criterion analysis methodologies, which resulted in the choice of AHP, for reasons previously treated.

This indication enabled the implementation of the fourth stage which consisted of the construction of AHP hierarchy that includes the decomposition of the problem in their common characteristics and the formation of hierarchy itself.

It is worth mentioning that given the importance for developing countries, a holistic approach to the issue of sustainability criteria were defined as the economic, environmental and social aspects.

In this phase were also selected experts for value judgments ranging from undergraduates, users of the facilities, until $\mathrm{PhDs}$ in management, environment, economy and safety engineering.

The use of individual judgment of each expert for the entire hierarchy is not convenient the extent that they have much knowledge of a single discipline, and therefore should not be called to answer for branches of the hierarchy over which they do not possess the necessary knowledge $[15,16]$.

It is noteworthy that in this research was adopted exclusive evaluator for the value judgments of the criteria in light of the main objective.

Likewise were adopted exclusive evaluators for the value judgments of the sub-criteria against each criterion and of the families of indicators for each sub-criterion.

The fifth stage was the procedure for data collection that has developed from personal interview with the experts following the presentation of the subject as well as the evaluation framework for sustainable school buildings.

Note that before the application of the instrument experts could make inquiries and suggestions for modifications according to their respective experiences and opinions[15].

In the next step the data obtained were processed and checked with respect to the test of consistency of AHP and in case of inconsistency the expert was then asked to perform a new fill.

At this point, it is important to note that the result of the evaluation of sustainability as shown in Fig. 3 drawn from the note received by each of the families of indicators, drawn from three possible levels: 0.0 - does not meet the basic requirements, 0.5 - meets the basic requirements and 
exceeds 1.0 the basic requirements[12].

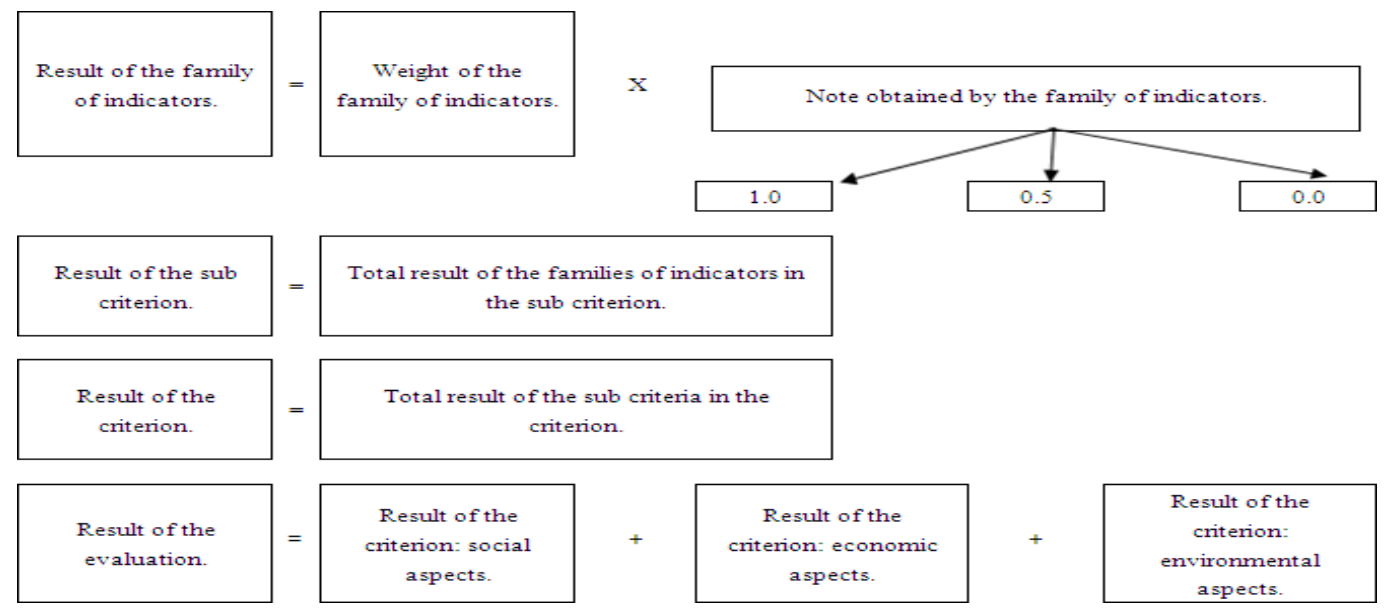

Figure 3. Determination of the final result of the evaluation

Table 3. Matrix of criteria, sub-criteria and families of indicators

\begin{tabular}{|c|c|c|c|}
\hline Main objective & Criteria & Sub criteria & Families of indicators \\
\hline \multirow{36}{*}{$\begin{array}{l}\text { Weightings of } \\
\text { assessment criteria, } \\
\text { sub criteria and } \\
\text { families of indicators }\end{array}$} & \multirow{11}{*}{$\begin{array}{l}\text { Economic } \\
\text { aspects }\end{array}$} & \multirow{6}{*}{$\begin{array}{l}\text { Operacional } \\
\text { investments }\end{array}$} & Annual budget development \\
\hline & & & Use of automatic systems \\
\hline & & & Budget plan/actual \\
\hline & & & Performance planning \\
\hline & & & Replacement of devices in end of live \\
\hline & & & Replacement by other similar devices \\
\hline & & \multirow{4}{*}{$\begin{array}{c}\text { Operacional } \\
\text { expenses }\end{array}$} & Budget plan/actual \\
\hline & & & Development of annual budget timing \\
\hline & & & Performance planning \\
\hline & & & Replacement of devices by other more efficient \\
\hline & & \multirow{3}{*}{ Eco management } & Water management system \\
\hline & \multirow{25}{*}{$\begin{array}{l}\text { Environme } \\
\text { ntal aspects }\end{array}$} & & Waste management system \\
\hline & & & Energy management system \\
\hline & & \multirow{5}{*}{ Water efficiency } & Water use performance \\
\hline & & & Innovative reduction water technologies \\
\hline & & & Water efficient landscape \\
\hline & & & Leak detection system \\
\hline & & & Use of automatic system \\
\hline & & & Renewable energy \\
\hline & & \multirow{3}{*}{ Energy efficiency } & Use of automatic system \\
\hline & & & Energy-efficient \\
\hline & & & Innovative reduction energy technologies \\
\hline & & \multirow{5}{*}{$\begin{array}{l}\text { Materials and } \\
\text { resources }\end{array}$} & Recycle material use \\
\hline & & & Local and regional materials \\
\hline & & & Renewable material \\
\hline & & & Resource reuse \\
\hline & & & Recycle material collection \\
\hline & & \multirow{5}{*}{ Waste and pollution } & Solid waste production performance \\
\hline & & & Emission generation performance \\
\hline & & & Innovative reduction waste and pollution technologies \\
\hline & & & Waste water production performance \\
\hline & & & Other waste production performance \\
\hline & & \multirow{4}{*}{ Sustainable site } & Infrastructure efficiency \\
\hline & & & Alternative transportation system \\
\hline & & & Land use \\
\hline & & & Relation between the building and its immediate \\
\hline
\end{tabular}




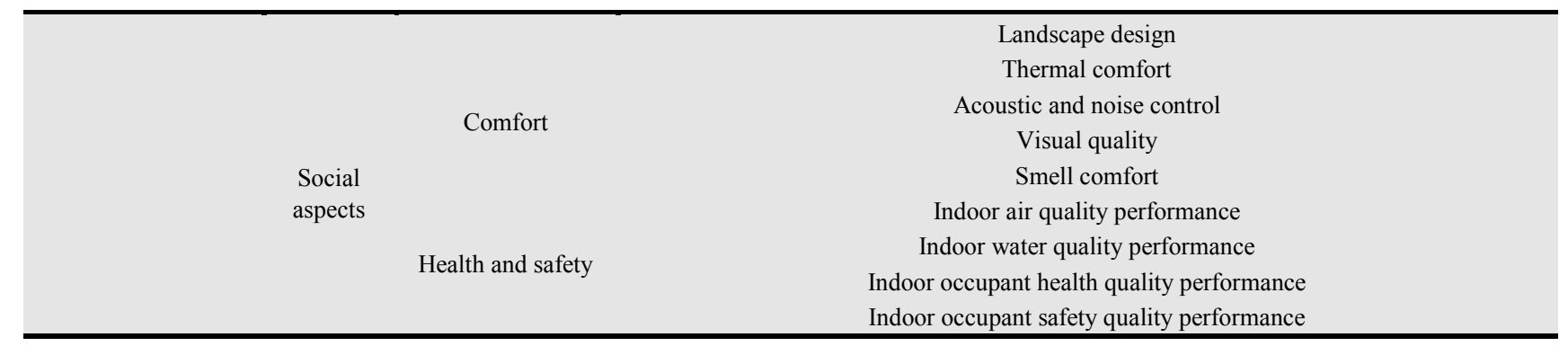

Table 4. Weightings of assessment criteria and sub-criteria

\begin{tabular}{llll}
\hline Main objective & Criterion/ Weight & Sub criteria & Weight \\
\hline & \multirow{2}{*}{ Economic aspects / 0,430 } & Operational investments & 0.215 \\
& & Operational expenses & 0.215 \\
& Social aspects / 0,140 & Comfort & 0.024 \\
Weightings of assessment & Health and safety & 0.116 \\
criteria, sub criteria and & & Eco management & 0.129 \\
families of indicators & \multirow{2}{*}{ Environmental aspects / 0,430 } & Water efficiency & 0.155 \\
& & Energy efficiency & 0.052 \\
& & Materials and resources & 0.013 \\
& & Waste and pollution & 0.064 \\
\hline
\end{tabular}

Based on the categorization criteria set out in the performance world-class systems is possible based on the percentage of points earned on the total number of points involved in the evaluation provide the following proposal for performance levels[12].:

a) Very sustainable $-80 \%$ to $100 \%$

b) Sustainable - from $50 \%$ to $79 \%$, and

c) In the path of sustainability - from $0 \%$ to $49 \%$.

Table 3 shows the evaluation framework for sustainable school buildings obtained in this study.

\section{Analysis of Results}

In respect to the results of the interviews, the weightings of the assessment items were calculated. The weightings of the criteria and sub-criteria are defined in Table 4.
As can be seen in the first level of the assessment matrix, environmental and economic aspects were ranked at the same importance, each one represents $43 \%$ of the total, and more important than the social aspects that represents only $14 \%$ of the total.

In the second level the result of the sub-criterion "water efficiency", considered the most important, demonstrates a good level of fitting to the local context, since the difficulties and costs involved with the systems of water supply in big cities.

Note that the result obtained for the sub-criterion "health and safety", indicates the awakening of the sense of importance and significance to the theme so necessary in developing countries.

Table 5 shows the differences obtained in the levels of importance to key aspects of the proposed methodology compared to the values found in the main systems available.

Table 5. Comparison: main systems (average) X model

\begin{tabular}{cccc}
\hline Assessment criteria & & Model main systems \\
\hline Energy efficiency & $5,2 \%$ & \\
Water efficiency & $15,5 \%$ & $12,7 \%$ \\
Indoor environment quality & $14,0 \%$ & $8,9 \%$ \\
Waste and material management & $8,7 \%$ & $16,5 \%$ \\
Eco management & $12,9 \%$ & $16,4 \%$ & $1,4 \%$ \\
\hline
\end{tabular}

\section{Conclusions and Recommendations}

Initially it should be noted the complexity observed in the process of assessing the sustainability of buildings to the extent that it happens in a context of multiple variables simultaneously acting as well as personal interpretations of multiple actors who are buoyed by their respective experiences and preferences.

The holistic approach used in this study fully customized to the context of the metropolitan region of Rio de Janeiro can produce significant positive impacts on social and economic area since it does not focus so heavily on minimizing environmental impacts as traditional models.

Also accordingly to the observations and findings carried out during the research is able to confirm that the process of assessing the sustainability of buildings effectively depends on several environmental, economic and social factors that vary from region to region, depending on the prevailing local context. 
Multi criterion analysis implemented with the AHP, to determine the relative importance of the aspects involved in a sustainability assessment of existing school buildings and supported by the opinion of experts and stakeholders, revealed it adequate to the extent that the situation demanded a perspective holistic and multidisciplinary.

From the evidence found during the search was concluded that the AHP method eases the understanding of decision-making by the actors involved and the meanings of the results.

The employment of the specialist unique for each segment of the hierarchical structure, with proven knowledge of the local context, showed to be adequate and simplified the mathematical treatment of data of value judgments by avoiding the use of complementary tools to AHP.

Regarding the results obtained for the first hierarchical level was possible to observe that there was no the expected uniform distribution of relative importance between the economic, environmental and social aspects.

The inferiority of the relative weight obtained by the criterion "social aspects" denotes not an inappropriate choice but an alignment of experts with standards implemented in developed countries where the social aspects do not have a significant weight since the majority population already have their basic needs met.

\section{Acknowledgements}

The authors gratefully acknowledge the assistance of the key actors who participated in the survey. They played an important role on the decision making process but mostly by shaping the research method and the AHP application to conform to future usage.

\section{References}

[1] O. Ortiz, F. Castells and G. Sonnemann, "Sustainability in the Construction Industry: A Review of Recent Developments Based on LCA," Construction and Building Materials, no. 23, 2009, pp. 28-39.

[2] G. K. C. Ding, "Sustentainable Construction - The Role Environmental Assessment Tools," Journal of Environmental Management, no. 86, 2008, pp. 451-464

[3] C. Menassa, "Evaluating sustainable retrofits in existing buildings under uncertainty". Energy and Buildings, no. 43, 2011, pp. 3576-3583

[4] J. Burnett, "City Buildings - Eco - Labels and Shades of Green!," Landscape and Urban Planning, no. 83, 2007, pp. 29-38.

[5] ASTM International - American Society for Testing and Materials. E 2114-01 - Standard, terminology for sustainability relative to the performance of buildings. 2001

[6] A. Haapio, and P. Viitaniemi, "A Critical Review of Building Environmental Assessment Tools," Environmental Impact
Assessment Review, no. 28, 2008 pp. 469-482.

[7] V. G. Silva, M. G. Silva, and V. Agopyan, "Evaluation of Buildings in Brazil: Environmental Assessment for the Evaluation of Sustainability," Built Environment, no. 3, 2003, pp. 7-18.

[8] A. Libovich, "Assessing green building for sustainable cities", In: World Sustainable Building Conference, 2005, Tokyo Proceedings... Tokyo: WSBC, 2005, p. 1968-1971.

[9] ULSF - Association of University Leaders for a Sustainable Future, "What is Talloires Declaration? 2005.

[10] BCSE - British Council for School Environments, "Sustainable Schools - Getting it Right." 2006.

[11] H. H. Ali and S. F. Nsairat, "Developing a Green Building Assessment Tool for Developing Countries - Case of Jordan," Building and Environment. no. 44, 2009, pp. 1053-1064.

[12] J. Gibberd, "Assessing Sustainable Buildings in Developing Countries - The Sustainable Building Assessment Tool (SBAT) and The Sustainable Building Lifecycle (SBL)," Proc. of The World Sustainable Building Conference, Tokyo, Japan, 2005, pp. 1605-1612.

[13] TÉCHNE. Avaliação ambiental. São Paulo: Pini, no. 133, 2008. ISSN 0104-1053.

[14] H. A. Simo, "Comportamento Administrativo: Estudo dos Processos Decisórios nas Organizações Administrativas," 1st ed., Rio de janeiro, RJ: Fundação Getúlio Vargas, 1965.

[15] H. G. Costa, "Multicriteria Decision Aid - AHP Method," 1st ed., Rio de Janeiro, RJ: Abepro, 2006.

[16] C. P. López, J. C. Requena and T. H. Giménez, "Multi-criteria Evaluation of The Environmental Performance of Conventional, Organic and Integrated Olive-growing Systems in The South of Spain Based on Experts Knowledge," Renewable Agriculture and Food Systems, no. 22, 2007, pp. 189-203.

[17] D. N. Tiwari, R. Loof and G. N. Paudyal "Environmental-Economic Decision-Making in Lowland Irrigated Agriculture Using Multi-criteria Analysis Techniques," Agricultural Systems, no. 60, 1999, pp. 99-112.

[18] T. L. Saaty, "The Analytical Hierarchy", 1st ed., Sao Paulo, SP: McGraw-Hill/Makron Books, 1991.

[19] T. L. Saaty, "The Analytic Hierarchy Process: Planning, Priority Setting, Resource Allocation", 2sd ed., New York: McGraw-Hill, 1980.

[20] K. F. Chang, C. M. Chiang and P. C. Chou, "Aspects of Adapting GBTool 2005 - Searching for Suitability in Taiwan," Building and Environment. No. 42, 2007, pp. 310-316.

[21] A. L. Vidal, E. Sahin, N. Martellin, N. Berhoune. and B. Bonan, "Applying AHP to select drugs to be produced by anticipation in a chemotherapy compounding unit". Expert Systems with Applications, no. 37, 2010, pp. 1528-1534.

[22] Y. Dong, G. Zhang, W. Hong and Y. Xu, "Consensus Models for AHP Group Decision Making Under Row Geometric Mean Priorization Method”. Decision Support Systems, no. 49, 2010, pp. 281-289. 